\title{
El aprendizaje del léxico español en los estudiantes lusófonos
}

\author{
J. AGUSTÍN TORIJANO \\ Universidad de Salamanca
}

\section{INTRODUCCIÓN}

El presente trabajo se enmarca en un amplio estudio, llevado a cabo hace unos meses, sobre los errores cometidos por estudiantes lusófonos (portugueses y, en mayor medida, brasileños) de español. Para ello, se analizó un corpus formado por más de 6000 composiciones escritas, pertenecientes a la llamada «parte escrita» del Diploma Básico de Español (DBE), correspondiente al nivel medio de los Diplomas de Español como Lengua Extranjera (DELE). Estos Diplomas son, como se sabe, títulos oficiales, acreditativos del grado de competencia y dominio del idioma, que otorga el Instituto Cervantes en nombre del Ministerio de Educación de España, y en los que la Universidad de Salamanca colabora con el Instituto Cervantes en la elaboración de los modelos de examen y en la evaluación de las pruebas para la obtención de los Diplomas de Español.

El estudio de la presencia del error léxico, al lado de los fonéticos/ortográficos y los morfosintácticos, constituye por sí solo un asunto de extraordinaria magnitud en cualquier estudio comparativo o, específicamente contrastivo, especialmente cuando la lengua materna (LM) de los aprendices es el portugués, tan aparentemente similar y, como se intentará demostrar, tan profundamente diferente al español. Apelando a la mera expresividad de las cifras, éstas revelan una existencia de error léxico en torno al 50\% del material componente de cada corpus. A modo de referencia numérica, es significativo el dato de que, de las más de 1700 muestras de habla de los candidatos al $D B E$ de São Paulo, un total de 918 están afectadas total o parcialmente por problemas de léxico, es decir un $53,75 \%$. Similar porcentaje se repite en el corpus del DSE de São Paulo (20 errores sobre más de 50 secuencias) o en el de Oporto (90 de 220).

En efecto, el léxico es el elemento de ambos idiomas que más deja traslucir la falsa idea de similitud y hasta de igualdad que se forjan muchos aprendices de sendas lenguas al aproximarse a la otra. Esta impresión se hace más patente en las producciones escritas (PE), destreza que refleja con más veracidad esa supuesta identidad del acervo léxico de ambos idiomas porque la proximidad -y hasta la identidad- es mucho mayor en la grafía que en el sonido.

El compartimiento de un origen y de un pasado comunes hace inevitable esta asociación, ${ }^{1}$ pero en realidad nos encontramos ante un inmenso artificio cuyo señuelo es la proximidad y cuyas consecuencias son un completo catálogo de falsos amigos que ponen de manifiesto la vigencia de la transferencia negativa.

1 El DRAE-1992 recoge un total de 193 entradas de origen portugués, entre las que diferencia las de procedencia propiamente portuguesa, pero también «antiguo portugués», «portugués dialectal», «gallego-portugués» $\mathrm{y}$ «brasileño». 
La descripción de los elementos léxicos nos permitirá realizar el contraste y la base de sustentación sobre la que podamos fundamentar la descripción y sobre todo la explicación de los errores cometidos.

La existencia de un caudal tan amplio permite y aconseja el establecimiento de partes, según sea la naturaleza del error, de tal forma que podamos así obtener una explicación válida a cada grupo de casos similares y no a la totalidad tomada en su conjunto, generalización más abocada al error.

\section{ERRORES LÉXICOS ORTOGRÁFICOS}

La proximidad lingüística de ambos idiomas, manifestada especialmente en las similitudes gráficas, produce un tipo diferenciado de errores léxicos, sin dejar de ser-además-morfológico. Son, por tanto, errores que detectan una asistematización de lexías, aunque las similitudes morfológicas sirvan de modo eficaz a la comunicación. Así, por ejemplo, si el informante escribe *professor por profesor no demuestra sino un desconocimiento del vocabulario de la segunda lengua (L2), de la misma manera que si el informante fuera francófono y produjera * professeur, o * professore si lo fuera de lengua materna italiana. La proximidad gráfica y fonética no puede ocultar la falta de sistematización de una forma léxica, pese a que sea sólo una letra o un fonema lo que la diferencie de la considerada correcta en la LM.

Como norma general, los errores de tipo ortográfico suelen deberse a una intervención de la interferencia, si bien hay casos en los que el modelo - mal aprendido- de la L2 produce desviaciones morfológicas por intraferencia ${ }^{2}$ o ultracorrección, como veremos.

Intentar agrupar los errores léxicos ortográficos por grafías o sonidos afectados sería quizá demasiado prolijo, por lo que reunimos en grupos más representativos muestras de errores que ejemplifican la presencia de un error que, sin ser grave o bloqueante, produce cierta sensación de retroceso en el avance de la interlengua.

Además, y no debe pasarse por alto esta cuestión, nos enfrentamos también con el problema de las llamadas faltas de ortografía, concepto sólo activado cuando entran en conflicto grafías que corresponden a sonidos homófonos en español, aunque no lo sean en portugués.

1. confusión de $b$ y $v$, apreciable con formas verbales diferenciadas en español y portugués: escrever, haver, dever, etc. y los imperfectos de indicativo de los verbos en -ar: cantava, falava, etc.;

2. presencia/ausencia de $h$.

3. confusión de las grafías $q u / c / c c$;

4. confusión de sonidos velares y palatales y sus grafías;

5. confusión de $l l$ y $l$, y de sus sonidos;

6. confusión de $n$ y $\tilde{n}$;

7. confusión de $c$ y $z$;

8. confusión de $r$ y $g / j$ por confusión de sonidos;

9. confusión de $s / s s / x$.

Ejemplificamos con algunas muestras de los corpus estos problemas gráficos.

2 Llamo intraferencia a la transferencia negativa o interferencia producida por la misma lengua que se estudia ( $c f$. infra y Torijano 2004, 2005 y 2006). 
1. *sus primeras palavras de ayuda; *Govierno; *recuperava el aire para hablar; *ya están escriviéndoles cartas y cartas; *su situación se encuentrava un poco mala; *el abuelo resvaló y está en un hospital; *ganar su dinero devidamente; *entonces yo enamorava Monica; *encontrarás mas travas; *te sirban a un mayor desarrollo; *la mejor nobidad es que no hay; *no tube respuesta; *Tubo otra oportunidad; *que prohiban para siempre los automóbiles allí; etc.

2. *están hayudando a vivir mejor; *te hecho de menos; *me hecho de menos todo eso; *[mis padres] te hechan de menos; * ¿recuerdas lo que hacíamos cuando héramos niños?; *Desde que has hido; *abló con ella y se quedó más triste; *a hecho [aquella noche] eso porque quería ser igual que su padre; *el trabajo que $a$ mucho deseaba; *aquella tarde él $a$ dicho que ha sido él; *y lo que no se vende hoy ay que hacerlo mañana; *una empresa de ay (= 'una empresa de ahí'); etc.

3. *frequentemente; *un día qualquier tu sabrás; *la question es incomoda, ¿no?; *quando la industria llega, los animales se van; *para las personas adequadas de esta ciudad; *estava con quatro años; *las consequências foran terribles; *cerrada y quase inacesible; *no sé quándo pero si dónde: aquí; *me acercé a la puerta pero no estava; *darse uno a otro sin condicciones; *son menos acceptables que las de antes; *fructos que resultarán; *otra gran falta de respecto; etc.

4. *todos juntos a la orija del lago; *ja escribí con anterioridad; *jo no puedo esperar más de un día; *se lo calló de la mano; *vacaciones de jullo (= ‘julio’); *lo cojí y lo llevé a mi casa; *recojer ahora los frutos de vuestro trabajo; *no es una sorpresa saber que te han elejido para eso; *como las plaias de Mallorca tan diferentes a estas; *hacer algo como por exemplo; *eso no lo digo tu padre, fue tu madre; *se levantó y así lo hijo; *no quería dijer siempre sí a todos; *Pusieron tajas más reducidas; etc.

5. *para levarlo a la fiesta; *te levaría las fotos del viaje; etc.

*siempre le decia que se llavase antes de salir; *para que se llevante el progreso; *no se allegró mucho por su nota; *una investigación excellente; *queria que su madre lle diera algo; etc.

6. *que tengas anoranza del Brasil; *el hombre camiña para atrás; *en la Alemanha; *una sobri$\tilde{n} a$; *para intentar enganarsi; *sólo quieren gañar dinero; etc.

7. *miró para su madrezita; *muchas vezes he tratado de escribir; *hize mucho por ella y por ti; *su vida se cambia en vazio, en autodestruicción; *La pobrezita chica, con esos ojos tristes; *esto no pareze tener muy buena soluicion; *estaba siempre en la cozina; *quinze; *treze; etc.

8. *recogeremos toda la ciudad a pie; *esas pajillas (= 'parrillas') tan españolas que nosotros llamamos rodízios; ${ }^{3}$ etc.

9. *se mostro esperto; *es más estranho no recibir notícias; *que ya te estranho; *no sabes cuanto te estraño ya; *una carta tan estraña como esperada; *esa fuerza estraordinaria de las madres; *una cara esquisita; *el progresso; *te permitan tus compromissos; *los años passados en Barcelona; etc.

Merece especial atención un tipo de error que, por una cuestión de distribución lingüística, afecta más a los candidatos brasileños que a los portugueses. Se trata de las confusiones entre /s/ y $/ \theta /$, pareja de fonemas que presenta una doble dificultad para los estudiantes residentes en comunidades seseantes, tanto por ser ésa la norma correcta en esas zonas (y también causa de error para aprendices hispanohablantes de su LM), como por la existencia de pares léxicos en ambos idiomas que presentan únicamente como marca gráfica de contraste $s$ en lugar de $z$.

3 En casos como estos dos se observa que los informantes han producido una desviación que, pese a tener como causa un problema fonológico, ha originado una aparente elección errónea del léxico. En efecto, dada la pronunciación de ciertas zonas de Portugal - especialmente de Lisboa hacia el sur-y sobre todo en Brasil, se produce una confusión por falsa identificación de sonido-grafía. 
Los estudiantes deben afrontar las diferencias entre el sapato portugués y el zapato español, lápis y lápiz, sáfio y zafio, sumo y zumo, Saragoça y Zaragoza, sarabanda y zarabanda, samarra y zamarra, Cádis y Cádiz, Fernandes y Fernández, Lopes y López, o Mendes y Méndez, etc., además de tener que interiorizar una reducción de las sibilantes portuguesas -más grafías y más sonidos- a las españolas - mucho más simples-y, por tanto, más susceptibles de hipergeneralización. Estas similitudes / disimilitudes producen errores léxicos en ambos sentidos: generalización errónea de las grafías $c$ y $z$, y de la grafía $s{ }^{4}$

Los errores gráficos a los que hacemos referencia son aquéllos que dejan traslucir cierta aproximación del estudiante a la forma correcta, aunque sin llegar a dominar un aspecto tan esencial como el fonético-ortográfico, que se convierte en causa de error, y, como decimos, pueden generalizar un uso innecesario de la grafía $s$ para intentar reproducir su sonido:

*la intensión de la maestra (= 'la intención'); etc. *no hay casas de sumo como aquí; *y darte un gran abraso;

*para que tu conosca; *no meresco, amigo, todas esas palabras buenas; etc.

pero es mucho más llamativa la hipergeneralización de grafías $c$ o $z$ como estrategia de reproducción de un sonido que los informantes reconocen como propio del español (sólo peninsular aunque quizá más respetado entre ciertos grupos de estudiantes), pero que creen mucho más abundante:

*estaba yo anciosa (= 'ansiosa'); *un gato siamez; *las personas cencillas como tu (= 'sencillas'); *famozos; *te envio muchos bezos (= ‘besos'); *en Brazil; *para Brazil; *en el mismo citio (= 'en el mismo sitio'); *le dio permicion (= 'permiso'); *Diego hacido [sic] castigado (= 'Diego ha sido castigado'); etc.

Y entre ambos grupos podríamos destacar ejemplos que constituyen la manifestación de una confusión general:

*pasando por una reseción (= 'recesión'); *y entonces reconocio las dos crusecitas de sus hermanos; *ya sabes que yo nesecito pocas cosas para ser feliz; etc.

\section{ERRORES DE SELECCIÓN LÉXICA}

La presencia de errores por causas léxicas es, como queda dicho, masiva hasta el punto de constituir una clara seña de identidad de un análisis contrastivo entre dos sistemas tan próximos. Piénsese en las diferencias que podría producir un análisis contrastivo entre el español y cualquier otro idioma lingüísticamente lejano, entre los que se establecen relaciones de muy diferente índole a las que nuestro análisis de interlenguas nos produce.

Además de las ya vistas muestras de secuencias erróneas por causas directamente relacionadas con problemas fonéticos y ortográficos, dividimos en dos grupos los contextos con error, según sea su causa por interferencia o por intraferencia.

4 No nos referimos aquí a errores léxicos debidos a la pura interferencia, que muestran incluso grafías o combinaciones inexistentes en español y que evidencian la absoluta ignorancia de la forma correcta de la L2:

*mi madre también empeçó a reír; *otra historia graçiosa de Pedro; *el vecino empeçó a reír; *mi hermana empeçó a mirarlo; *un fuerte abraço; * el puesto que tanto deseabas fue alcançado; *yo estaré a buscar trabalho; *la vida en el planeta Terra estará ameaçada; *el crescimento en mi país; etc. 


\subsection{ERRORES POR INTERFERENCIA}

Pese a que cabría establecer múltiples subdivisiones basadas más en diferencias circunstanciales que en categorías apriorísticas, optamos por esta clasificación más esencial que permita de forma más práctica conocer la interlengua objeto de nuestro estudio.

De este modo, debemos considerar errores de selección léxica por interferencia aquéllos que se producen cuando el hablante apenas procesa las unidades del sistema de su L1 y lo aplica en el contexto de la L2, dando de este modo origen a secuencias en las que a veces corre peligro no sólo la corrección en términos generales sino también la capacidad de comunicación, si bien en muchos casos puede llegarse a solventar con estrategias de redundancia, de repetición, paralingüísticas, etc.

Dada la inoportunidad de trasladar aquí la totalidad de esas secuencias, exponemos una limitada representación de ellas:

*e fue procurar su hijo; *pero acreditaba yo; *la queda en las exportaciones (= 'la caída'); *luego no tendremos oxigenio; *el cual tanto almejabas (almejar, 'desear, ansiar' <alma +-ejar); *pero no con tantos afeites; *avancios en nuestras cartas; *no me gusta el avanzo (avanço) demasiado de la vida; *destruyendo la camada de ozonio; *y tenerlo más tiempo en mi cuelo [a su bebé] (= 'regazo'); *nuevos problemas van a ser gerados; *se han hecho esfuerzos para atinguirmos un equilibrio; *que nosotros intentemos defensar; *el aquecimiento de la Tierra (= "el calentamiento'); *Brasil tiene ainda la floresta amazónica; *brindar al nuestro succeso; *al folear las páginas de su libro; *progredir menos y vivir mejor (= 'progresar'); *la tecnología y el progreso son ferramientas útiles; *la selva sufría los prejuizos de la accion del hombre (port. prejudicar, 'perjudicar'); *espero reverla; *hacemos parte de la naturaleza; *Sucede que quando los veo están borrachos y ponen la culpa en el vino; *Su padre cuando ojó para el lado (= 'miró; port. olhou, de olhar, 'mirar'); *con una fantasía de torero (= 'traje, disfraz'); *Cientistas españoles hicieron la decubierta del siglo; *nuestros mestres de español en Brasil son jóvenes; *la vida en el planeta Terra estará ameaçada; *países en crise económica; *una terraza muy ensolarada; *nuestro pais no puede se isolar del resto por el idioma; *los fatos nos lo dicen (= 'los hechos nos dicen); *estaban prontas (= 'preparadas); *se aprontó con la niña (= 'se preparó, dispuso'); *estoy con muchas saudades; *el próximo final de semana; *sobrevivência propia; *podían hacer su sobrevivência; *es necesario una tomada de decisión; *tenía una bella varanda; *que tomes muchas providencias (= 'precauciones'); etc.

Es apreciable una evidente estrategia de calco, hasta el punto de que a veces el valor semántico queda supeditado a una mera proximidad gráfica, sin la cual sería imposible considerar efectuada la comunicación. La interferencia es pura, porque los significantes pueden coincidir con los de las voces españolas: procurar; acreditaba; la queda; afeites; camada; cuelo; succeso; prejuizos; torcendo; etc., lo cual lleva al problema de los falsos amigos, tratados más adelante.

Asimismo, llamamos la atención sobre la presencia del fenómeno de la inexistente monoptongación (de vocales /e/ y /o/ procedentes de breves tónicas latinas), correcta en portugués pero incorrecta en español, y sobre la que hablaremos más extensamente al hablar de los errores por intraferencia (2.B.b. La diptongación).

Se constata, pues, que los errores léxicos por interferencia aparecen normalmente en las primeras fases de aproximación a la lengua, aunque esto a veces puede llevar a engaño, al solapar el problema de la fosilización que crea la falsa impresión de errores primarios, cuando en 
realidad no son sino sistematizaciones equivocadas que se repiten a veces de manera incomprensible en estudiantes de español con un apreciable grado de dominio.

\subsection{ERRORES POR INTRAFERENCIA}

El análisis del corpus muestra la existencia de una significativa cantidad de secuencias que pertenecen a una fase siguiente (o a un conjunto de ellas) en el proceso de avance de la interlengua. A diferencia de las vistas más arriba, éstas descubren la intervención de cierto tratamiento en las formas léxicas por influencia de las características de la L2 o, al menos, de aquéllas que el hablante le atribuye, dependiendo de su grado de interiorización. El aprendiz comienza a conocer elementos, estructuras, construcciones, unidades léxicas de la L2 que, de manera automática o premeditada, imprime -bien que insuficiente o incorrectamente- a los contextos que estarán más o menos cerca de la LO según sea el grado de corrección de éstos.

En su mayoría son errores generados por la combinación de dos estrategias conjuntas: por un lado, la del trasplante de un elemento de la L1 considerado válido y, por otro, la aplicación parcial de lo que el aprendiz considera necesario para transformar su elemento original de L1 en el elemento exigido en la L2. El resultado es un producto de la interlengua.

Esas ligeras o profundas modificaciones que el aprendiz aplica se enmarcan en una gama que abarca mínimos cambios hasta transformaciones mayores, que podríamos graduar de la siguiente manera:

1. la eliminación o adición de tildes existentes en portugués pero no en español, y viceversa: conseqüência (Brasil)/ consequência (Portugal) > *consequéncia; quedei > *quedéi; etc.

2. transliteración simple de elementos gráficos que corresponden a sonidos comunes o relacionados:

compartilhando $>*$ compartillando; sobrinha $>*$ sobriñ $;$ julho $>*$ jullo; olhar $>*$ ojar; a escolha $>$ la *escoja; viagem $>*$ viajen; sucesso $>*$ suceso; as queimadas $>$ las $*$ quemadas; etc.

3. transformaciones sistemáticas, especialmente las referidas a sufijación:

saudade $>$ *saludad; conscientização $>$ *concientización; quitação $>*$ quitación; olvido, esquecimento $>$ *olvidamiento; inesquecível $>$ *inesquecible ( = 'inolvidable'); etc.

4. aplicaciones generalizadas (hipergeneralización) de elementos pertenecientes a otros paradigmas, modelos o subsistemas:

destruição $>$ *destruyción; *destruición; desenvolvimento $>$ *desarrollamiento; desrespeito $>$ *desrespeto; progredir $>$ *progredar; ou seja $>$ *ou sea; etc.

Se observa, por tanto, y quizá más que en ningún otro aspecto del léxico, esta estrategia de aproximación desde la L1 del estudiante hasta la LO, lo que produce los denominados casos frontera, estudiados por A. Durão (1999), y que constituyen un fenómeno que guarda cierta proximidad con el de las palabras heterosemánticas o falsos amigos, aunque no siempre ambos fenómenos son identificables, dado que el estudiante no sólo implanta la forma de su LM en la L2 -como ocurre con éstos- sino que intenta adaptarla a la nueva norma.

A modo de muestra, ofrecemos un cuadro resumen de estos casos frontera, que suelen aparecer con mucha frecuencia en producciones de estudiantes lusófonos, es decir, en su IL, presentadas entre la forma correspondiente de la LM y la considerada correcta en la LO. 


\begin{tabular}{|c|c|c|}
\hline FORMA EN LA LM & FORMA EN LA IL & FORMA EN LA LO \\
\hline a grande parte de & la grande parte de & la mayoría \\
\hline aínda que & aunque & incluso \\
\hline almejar & almejabas & desear, anhelar \\
\hline ao invés & al invés & en vez de \\
\hline avanço & avanzo, avancio & avance \\
\hline boneca & boñeca & muñeca \\
\hline caminhada & caminada & paseo \\
\hline caminhão, camião & camiñón & camión \\
\hline caminhar & camiñar & caminar \\
\hline carinhos & cariños & besos y abrazos \\
\hline colo & cuelo & regazo/ cuello \\
\hline comboio & comboyo & tren \\
\hline compartilhar & compartillar & compartir \\
\hline correios & correos & correo \\
\hline costa Atlântica & cuesta Atlántica & costa Atlântica \\
\hline dançar & danzar & bailar (no clásico) \\
\hline descobertas & descubiertas & descubrimientos \\
\hline desenvolvimento & desarrollamiento & desarrollo \\
\hline desrespeito & desrespeto & falta de respeto / grosería \\
\hline em boa hora & en buena hora ${ }^{5}$ & enhorabuena \\
\hline engraçada & engrasada & graciosa \\
\hline escolha & escoja & elección \\
\hline estar certo & estar cierto & estar seguro / tener razón \\
\hline estou a pensar (Port.) & estoy a pensar (Port.) & estoy pensando \\
\hline falar que & hablar que & decir que \\
\hline fazer parte & hacer parte & formar parte \\
\hline ficar (feliz, rico...) & quedar (feliz, rico...) & ponerse / hacerse / volverse \\
\hline ficar aborrecido & quedarse aburrido & enfadarse \\
\hline folhear & folear & hojear \\
\hline ganhar & gañar & ganar \\
\hline ganhar (um regalo) & ganar (un regalo) & recibir \\
\hline inesquecível & inesquecible & inolvidable \\
\hline jornáis & jornales & periódicos \\
\hline Julho & jullo & julio \\
\hline locáis & locales & lugares \\
\hline meia & media & seis (números de teléfono) \\
\hline mesmo & mismo & incluso / además de \\
\hline montra & muentra & escaparate \\
\hline mudança & mudanza & cambio \\
\hline muito & mui & muy / mucho \\
\hline muito bom, mau & mucho bueno, malo & muy bueno, malo \\
\hline olhar & ojar & mirar \\
\hline pagamento & pagamiento & paga \\
\hline parabentear & parabenizar & felicitar \\
\hline paradoxo & paradojo & paradoja \\
\hline
\end{tabular}

5 La secuencia completa es * ¿En buena hora pelos triunfos!, lo que elimina la posibilidad de la exclamación irónica del tipo en buena hora se me ocurrió..., mucho menos frecuentes en portugués 


\begin{tabular}{|l|l|l|}
\hline perceber & percibir & entender / notar \\
\hline perda & pierda (sust.) & pérdida \\
\hline permissão & permicion & permiso \\
\hline população & populación & población \\
\hline prazer & plazer & placer / gusto \\
\hline relógio & relojio & reloj \\
\hline rever & rever & volver a ver \\
\hline rodízio & pajillas & parrillas \\
\hline rosto & ruestro & rostro \\
\hline saudade & saludad & saudade, nostalgia \\
\hline se tornar & tornarse & volverse \\
\hline sobrinha & sobriña & sobrina \\
\hline sucesso & suceso & éxito \\
\hline também não & también no & tampoco \\
\hline tão logo & tan luego & tan pronto como \\
\hline taxas & tajas & tasas \\
\hline ter & tener & haber (auxiliar) \\
\hline ter saudade & tener saudade & echar de menos / tener nostalgia \\
\hline viagem & viajem, viajen & viaje \\
\hline
\end{tabular}

Podría afirmarse que el fenómeno consiste en una combinación de los efectos de la intraferencia sobre la interferencia de la LM, en la medida en que el estudiante toma el modelo de su lengua de origen y lo moldea según las nuevas circunstancias, no suficientemente aprendidas, de la lengua de destino.

Como veíamos en el caso de los errores por interferencia, también los producidos por causas propias de la L2 suponen una presencia cuantitativa considerable, por lo que nos limitamos a trasvasar aquí una mínima selección de tales secuencias:

*sin preocuparse con las consequéncias; *se quedó roja delante de mí; *recibí su carta y me quedéi muy contento; *las razones deso olvidamiento están en los nuevos valores; *estamos con muy saludad de ti (= 'te echamos mucho de menos'); *Estoy muerta de saludad; *quiero estar contigo compartillando las cosas buenas (= compartilhar, 'compartir'); *hasta breve (= 'hasta pronto'); *ser llevado en cuenta ( = 'ser tenido en cuenta'); *la empresa hizo una buena escoja contigo (= 'elección, selección'); *las descubiertas de vacunas (= 'descubrimientos'); *deseo que tenga suceso (= 'éxito'); *espero que hagas mucho suceso; *la quitación de los árboles (= 'la tala'); *el sueño de nuestro viajen se tornó una calamidad; *es lo que llamamos cualidad de vida ${ }^{6}$; para mejorar la cualidad del aire; *todo esto es un desrespeto a la vida; *los peligros de las quemadas [de bosques] (= 'incendios'); *haciendo quemadas; *no, no: sin la concientización de todos el Brasil no crecerá; *han hablado la misma cosa (= 'han dicho'); *son cosas lógicas, hasta que obvias = 'incluso, hasta'); etc.

La importancia de este hecho se debe a ser el motor de la creación de formas nuevas, mezcla de las ya existentes en ambos idiomas y que son la base de esa lingua franca llamada popularmente portuñol.

6 Los valores de las formas españolas cualidad y calidad están representados en portugués por una única forma qualidade. 


\subsubsection{Errores generalizados}

La abundancia de ejemplos, escasamente representada por los casos arriba mostrados, se produce tanto por lo que respecta a los términos temáticos de las PE solicitadas - que, lógicamente, aparecen repetidos en una frecuencia forzada y por tanto anómala por las instrucciones dadas-como a las voces genéricas, patrimoniales, esperables en contextos más variados.

La extensión de nuestro corpus nos permite comprobar que, independientemente de aquellos errores inducidos por los temas obligatorios de las producciones escritas (que serían considerados errores causados por elementos del propio proceso de enseñanza/aprendizaje o PEA), es muy sencillo agrupar aquellos otros de carácter general que serían susceptibles de aparecer en otros contextos, lo cual probaría su arraigo generalizado en la interlengua colectiva que analizamos. Exponemos a continuación los casos de tres construcciones léxicas especialmente significativas que dan idea del panorama de ciertos problemas básicos en el plano léxico.

1. Es destacable, en primer lugar, la falta de sistematización de los usos normativos de verbos semiatributivos españoles como ponerse, hacerse, volverse, etc. con atributos (o complementos predicativos, según algunos autores ${ }^{7}$ ) como contento, triste, furioso, nervioso, rico, loco, etc., neutralizados todos en quedar, por ser éste uno de los valores del verbo portugués ficar, de extraordinaria polisemia en esa lengua. No extraña, por tanto, la presencia de múltiples secuencias con este tipo de error:

*de repente se quedó con mucha dolor de cabeza; *Me quedaría muy contento si estuvieras aquí; *`Vas a quedarte rico!; *se quedo furiosa; *como me quedé feliz; *quedó se com algunas dolores; *me quedé sorpresa; *tu vida queda más tranquila; *se quedó muy nervioso; *mi madre se quedó colorada; *en mi casa quedaron orgullosos; *muchos otros [amigos] quedaron novios; *después quedaron sabiendo; *la casa se queda cerca del correo central *el niño quedó sorpreso; *Maria quedó con el gallo; etc.

Se trata, pues, de errores que no deben ya considerarse de pura interferencia, en la medida en que el aprendiz ya aplica elementos de la L2, como son las desinencias verbales, y también la traducción que, al ser incorrecta, consecuentemente produce el error.

2. Otro ejemplo relevante de este tipo de errores de unidades léxicas generales lo constituye el verbo portugués recordarse de, cuasi sinónimo de lembrar, que la mayoría de los aprendices utiliza de forma incorrecta por cuanto hace uso del verbo y su régimen de su L1. Sin embargo, le aplica características que, como la diptongación y el uso de los pronombres, son ya propios de la L2 aunque el resultado es una desviación generalizada que, sin imposibilitar la comunicabilidad, produce sensación de error, precisamente por su alta frecuencia de aparición:

3. Una tercera evidencia de este fenómeno surge al estudiar la existencia de secuencias de error debidas a la confusión de los verbos ser y estar, tan problemáticos para alumnos de

7 Mientras Gómez Torrego (1998) prefiere seguir la denominación tradicional y terminológicamente más coherente de atributo, Bosque et al. (2000) optan por referirse a ellos como complementos predicativos, dado que con muchos verbos no son conmutables por el pronombre $l o$, una de las características esenciales de los atributos. 
casi todas las procedencias lingüísticas pero, en teoría, no demasiado complicados para informantes lusófonos, en cuya lengua la distribución y uso de estos verbos son similares a los del español. Sin embargo, y éste puede ser un ejemplo de la utilidad y validez del análisis de errores, las evidencias revelan que también entre dos lenguas como éstas, estamos ante un problema de los que llamamos pares biunívocos, cuyos dos elementos son, en grado más o menos equivalente, problemáticos: ser/estar, por/para, el/la, etc.

El apriorismo de las deducciones no debe condicionar en absoluto el rigor ni el enfoque del estudio. Los verbos ser y estar son muy productivos, por lo que suelen enseñarse en las primeros fases del proceso de enseñanza/aprendizaje (PEA), pero, obviamente, esta prontitud no tiene por qué significar el éxito en su interiorización.

Por otra parte, ambos verbos tienen, como decimos, usos similares, aunque quizá, nuevamente, éste sea el origen del problema. Así, por ejemplo, la formación de la voz pasiva en portugués no se concibe exactamente igual que en español, porque, además de la presencia fundamental del verbo ser -en la llamada voz passiva de acção-, se reconoce la intervención del verbo estar, en lo que los gramáticos llaman la voz passiva de estado (Estava assustado pelo problema).

Ambas modalidades de voz pasiva («analítica» frente a la «sintética», equivalente ésta a nuestra «pasiva refleja») tampoco se combinan exactamente como en español, dado que se prefiere decir

O meu país é cortado pelos trópicos,

cuya traducción al español recomienda vivamente el uso de está.

Observemos algunos de los abundantes ejemplos de esta confusión:

*estoy novia de un mozo; *hoy estoy novio de Marisa; *este país esta una vergüenza; *el colegio esta muy difícil; *no está corecto esta información; etc.

*son totalmente contra cualquier tipo de racismo; *no soy contra el progreso; *soy a favor de la afirmación; *es también muy remunerado; *él debe ser loco; *El Brasil és divido en la actualidad en cinco estados; * ¿la oficina es muy lejos de su casa?; *un empleo que [...] es cerca de mi casa; *son relacionados a la salud; etc.

\subsubsection{La diptongación}

Como veremos más adelante, el problema de los falsos amigos ha suscitado diferentes intentos de explicación, para lo que se ha recurrido tradicionalmente a la interferencia, aduciendo para ello la estrategia de la traducción directa como vía de disponibilidad de los elementos léxicos necesarios, tanto en la producción como en la comprensión. Sin embargo, y como consecuencia de la escasa distancia interlingüística entre los dos idiomas, el aprendiz pone en funcionamiento recursos posteriores, más elevados o avanzados, para la formación o creación de palabras, para lo cual sigue también las normas - bien o mal sistematizadas- de la L2, lo que hace que la interferencia dé paso a la intraferencia como la causa de estos errores.

Es especialmente visible este segundo proceso en las producciones vinculadas a uno de los errores con mayor vocación de fosilización, incluso en hablantes considerados casi bilin- 
gües: la diptongación hipergeneralizada. Constituye una estrategia extraordinariamente abundante en las secuencias de aprendices que intentan aplicar de manera indiscriminada la diptongación de /e/ y /o/ tónicas provenientes de breves tónicas latinas. Su existencia se debe al recurso de superación de un fenómeno inexistente en portugués pero abundante en español, aunque no hasta los límites supuestos por el estudiante lusófono. Sirva como caso paradigmático el ya famoso (y auténtico) error de *cueca-cuela, evidente generalización ultracorregida del nombre del popular refresco norteamericano, al aplicarle una diptongación hipergeneralizada y, por tanto, inexistente en español.

A fin de poder comparar ambos problemas, el de la monoptongación por calco (propio de la interferencia, como ya dijimos) y el de la diptongación por intraferencia, ofrecemos sendas series de secuencias que, a modo de muestras, den idea de la extensión de este tipo de desviaciones:

*con la morte de la vida vegetal; *cuidar mucho mas la terra; *la terra de tus padres; *la vida en el planeta Terra estará ameaçada; *el crescimento en mi país; *ella nunca estuvo en Marrocos; *tenerte en mi casamento; *era como una playa deserta; *han obtenido el posto; *hay que plantar una semente para cada arbol cortado; *los doños de los coches; *sus doños [...] se preocupan; *mi deseo es verte logo que pueda; *y logo estoy de vacaciones; *nuestro amigo fue al solo (= 'suelo'); * para que en el día seguinte; *podía verle un dente negro; *sin que mi abuela percebera; *venir novamente al Brasil; *vino de encontro; * ¡Buena sorte!; etc.

El fenómeno contrario, menos frecuente, produce un efecto de transitorio desconcierto en el hispanohablante, en la medida en que se encuentra con una transformación totalmente inesperada, incomparable, por otra parte, con hechos de habla de lenguas circundantes. La desconexión comunicativa, aunque breve, es a veces tal que produce incomprensión por confusión con otras voces:

*La cuesta atlántica es más rica; *El rey tuve que fermar un documiento nuevo; *momientos que no olvidarás; *Esto es porque quiero estudiar mi país y el momiento histórico; *mi ruestro se puso rojo; *la llevara en su miente; *el plan de educación que tenías en miente; *y tenerlo más tiempo en mi cuelo [a su bebé] (= port. colo, 'cuello'; 'regazo'); *un hombre muy esfuerzado; *la pierda total de poder (= port. perda, 'pérdida'); *estudiar mas hueras (= port. horas); etc.

La confusión de ambos fenómenos se ejemplifica de manera muy plástica en las dos variantes alomórficas del sufijo nominalizador-mento/-miento, doblete problemático para estudiantes como los lusófonos, en cuya L1 no ha lugar la forma diptongada. Esto es especialmente conflictivo cuando, precisamente, ésta es la forma mayoritaria en español (aparte de la complicación producida por las voces que se admiten con las dos formas), en una proporción de 1000 sobre 20, respectivamente, según algunos autores (cf. I. Bosque y V. Demonte, 1999). Así, el aprendiz lusófono se ve repetidamente desorientado ante lo que aparenta ser una falta de criterio en la formación y uso de un sufijo que, a menos que le dedique un estudio pormenorizado, tanto sincrónico como diacrónico, le parece regido por leyes arbitrarias.

Tal impresión se ve confirmada cuando descubre que la norma básica que afirma el origen verbal del sufijo tampoco es siempre exacta ni cierta, por lo que se produce una nueva 
estrategia de aproximación o de tanteo que es válida para solventar una necesidad de comunicación, pero que contribuye a la fosilización de un error que, previsiblemente, acompañará al hablante durante un largo tiempo.

\subsubsection{Los falsos amigos}

Como ya hemos apuntado en diferentes ocasiones, las características interlingüísticas que definen las relaciones entre el portugués y el español reúnen las condiciones idóneas para la existencia de las voces heterosemánticas, es decir, los más popularmente llamados falsos amigos o falsos cognados, como se prefiere denominarlos en portugués - quizá de forma más correcta, por cuestiones etimológicas que no discutiremos aquí-, algunos de los cuales ya hemos tratado de forma particular, como en el caso de las conjunciones y locuciones conjuntivas.

Efectivamente, las proximidades y coincidencias espacio-temporales y de todo tipo entre ambos sistemas no podían sino producir similitudes extraordinarias aunque no perfectas, lo que, una vez más, se convierte en causa de dificultad en el aprendizaje de ambas lenguas por parte de los hablantes de cada una de ellas.

No debe sorprender, por tanto, que entre dos lenguas que comparten un $90 \%$ de sus respectivos caudales léxicos, muchas de las voces hayan seguido historias paralelas y análogas, aunque otras muchas hayan iniciado -en diferentes etapas de su evolución- caminos divergentes, cargándose de significados o valores nuevos, en procesos que podemos clasificar en tres grupos diferentes:
a) falsos amigos parciales
b) falsos amigos de uso
c) falsos amigos totales

\section{a) falsos amigos parciales}

Denominamos así a aquéllos pares de palabras de forma idéntica o similar que, además de mantener los significados comunes, añaden a los existentes uno o varios más en sólo una de las lenguas. Es decir, que, compartiendo igual o similar significante, su significado es sólo en parte diferente (o, lógicamente, parcialmente parecido) en la otra lengua o presenta un segundo significado sí compartido por ambas. Los casos son innumerables, pero sirvan de ejemplo los siguientes:

criar: además del significado de criar posee también el de crear.

guarda-costas: este compuesto, que alterna con el adjetivo sustantivado guarda-costeira, presenta dos significados que pueden ocasionar problemas entre sí, porque, aunque efectivamente puede traducirse por el español guardacostas, mantiene con plena vigencia el significado de guardaespaldas, lo cual puede, según el contexto, inducir a error, aunque sea parcial.

ligar: igual que en español, este verbo tiene en portugués el valor de 'atar, sujetar', si bien añade los de 'llamar por teléfono', 'encender un aparato eléctrico o un motor', o 'prestar atención a algo'. mariposa: no significa exactamente lo que en español entendemos por tal, lo cual lo convertiría en un falso amigo. Sin embargo, sí se refiere a un insecto lepidóptero con la forma de la mariposa, aunque de tamaño considerablemente mayor, de color gris ceniciento, y siempre nocturna, por lo que denotativa y connotativamente se aleja sensiblemente del concepto en español, expresado en portugués con el término borboleta. El falso amigo parcial procede, significativamente, del español. 
pantalonas: lo que en español expresamos con esta forma (aunque en masculino) se designa en portugués con calças. No obstante este significante sí se refiere a una prenda de vestir, con dos patas, aunque sólo es un tipo de pantalón. Existen unas calças pantalonas, caracterizadas por la mayor amplitud de sus patas.

parcela: además del significado de 'parte pequeña, fragmento', esta voz aporta sendos valores más en cada una de las dos lenguas: 'división de terreno' en español, frente a 'mensualidad, cuota, pago fragmentado' en portugués.

tesón/tesão: independientemente de que compartan el valor de 'tenacidad, constancia', la forma portuguesa añade un valor más que la separa radicalmente de la española. Tal es así que si un lusófono produce una sentencia como *tiene problemas de tesón, su receptor hispanohablante estará ignorando el significado de 'erección masculina, potencia sexual', del mismo modo que un hispanohablante podrá ser igualmente malinterpretado en el caso opuesto, lo que ratifica el problema de comunicatividad característico de estos falsos amigos.

\section{b) falsos amigos de uso}

Forman parte de este grupo los binomios de significante equivalente o parecido y significado mantenido idéntico, pero no así su uso pragmático-comunicativo, lo que, en buena medida, es también una separación del camino común.

Se trata, en definitiva, de pares de voces que, compartiendo el significado denotativo, han cambiado su valor o, si se prefiere, el sentido o uso, que el significante pueda esconder tras sí. Es ésta cuestión indudablemente relevante, especialmente cuando afecta a hablantes de niveles altos de conocimiento de las lenguas y a los que ya les puede ya exigir un alto grado de destreza también de tipo pragmático en el uso de la lengua.

No es que una voz no signifique lo esperado, sino que debe calibrarse también qué implica, qué uso ha adquirido en determinado contexto. Este asunto se carga de mayor trascendencia cuando tenemos en cuenta que en el portugués (y en el español) de ambos lados del Atlántico, las mismas palabras pueden ser usadas con el mismo significado, pero se prefiere usar otras para evitar malentendidos, situaciones incómodas, etc., de forma que, coloquialmente, podríamos decir que «significan y no significan lo mismo». En resumen, podríamos afirmar que su principal problema es su poder de hacer elevar o descender el nivel pragmático de una conversación.

Los ejemplos se multiplican, pero veamos una mínima muestra:

buraco: la presencia de este sustantivo en una secuencia producida por un lusófono no genera problemas de comprensión global, excepto el que plantea la cuestión del registro socio-lingüístico de la voz, perteneciente a un nivel coloquial-vulgar en español. El uso del término en español no es similar al que recibe en portugués, por lo que se produce un error.

culinaria/culinária: aunque de relativamente reciente presencia en nuestra lengua (el DRAE la introduce en 1884), la voz significa exactamente lo mismo en ambos idiomas: como sustantivo 'arte de guisar' / 'a arte de cozinhar', y como adjetivo 'perteneciente o relativo a la cocina' / 'da cozinha ou a ela relativo' o 'pertencente ou relativo a cozinha'. Pero ha de considerarse un falso amigo de uso porque es frecuente leer y oír secuencias como eu gosto muito da culinária desta região, contexto modelo de justificación incorrecta del falso amigo * me encanta la culinária de esta región, donde el español estándar prefiere la voz cocina, o, en su caso, comida.

don/dom: este término honorífico presenta el mismo significado en ambos idiomas, pero en portugués la pragmática lo reserva socialmente para anteceder a nombres de reyes, nobles y personalidades eclesiásticas, frente a la extensión y generalización en español.

morar: con el significado de 'habitar, vivir' en ambas lenguas, se detecta una considerable diferencia de uso. Mientras en portugués el término y sus derivados gozan de una altísima fre- 
cuencia, en español no pueden considerarse sino limitados a contextos arcaizantes o poéticos y religiosos, lo que los convierte en falsos amigos de uso.

pesquisa: pese a que algunos diccionarios portugueses atribuyen el origen de esta palabra al español pesquisa, no es voz que goce de especial vigencia en nuestro idioma. Sucede que no sólo contamos con el sustantivo, sino también con el verbo (pesquisar) y con el adjetivo deverbal correspondientes (pesquisidor), y aun con el compuesto juez pesquisador. Por su parte, el portugués hace uso, igualmente, de pesquisa, pesquisar, pesquisador y pesquisamento. Existe, por tanto, una relación igualatoria de significantes y de significados que haría aceptable, denotativamente, el uso de la voz y sus derivados en cualquiera de los idiomas. Pero no ocurre así. La vasta presencia del término en portugués no puede igualarse con su escasa vigencia en español, hasta el punto de que si una secuencia en español muestra la voz, por ejemplo en contexto de investigación universitaria, estaríamos produciendo una desviación de registro del uso social pretendido. Su utilización parece reservarse a situaciones detectivescas, más o menos profesionales.

quarto: la proximidad y hasta identidad semántica no plantea mayor problema cuando no es preciso diferenciar una habitación de un cuarto, especialmente en contextos coloquiales o domésticos. El conflicto surge en contextos en los que es necesario diferenciarlos, como puede ser en un hotel, donde el turista hispanohablante sentirá una perturbación en la comunicación cuando el botones lo acompañe a un quarto, en lugar de a una habitación. El nivel de la conversación habrá sufrido un descenso.

assistenta: se produce un problema de uso cuando se aplica a contextos laborales, con el valor de 'ayudante femenina', en secuencias del tipo asistenta del director del banco, *assistenta del jefe de producción, etc. El uso del femenino ha producido un falso amigo de uso y, al menos socialmente, parece también que hace descender el nivel pragmático.

Pueden ilustrar esta variante de los falsos amigos ejemplos como los siguientes:

*mi morada es tuya; *estoy morando solo en un piso; *estoy morando próximo al terminal de metro; *moraba en una finca con sus padres; *e con pantalonas curtas color de naranja; *hacer un barullo; *la Floresta Negra en Alemania; *nuestra floresta amazónica está se acabando; *Brasil tiene ainda la floresta amazónica; *rios, lagoas, oceanos y florestas; *ahora soy una asistenta (= 'ayudante') en otro banco ${ }^{8}$; etc.

\section{c) falsos amigos totales}

Por último, pero sin duda no en importancia, debemos dedicar un análisis al problema de los falsos amigos en sí mismos, o falsos amigos totales, que constituyen un considerable escollo en la sistematización del léxico de ambos idiomas para los estudiantes de LM opuestas. Nuevamente debe hacerse hincapié en la relación de supuesta identidad entre estos pares de voces similares o iguales en su forma, pese a que los significados o valores que aporta cada uno de ellos no sean los esperados o los generalizados por el hablante.

La consabida cercanía lingüística de ambos sistemas es, como queda dicho, razón suficiente para explicar los dos fenómenos más visibles que acontecen entre el portugués y el español. Por un lado, la existencia real de una facilidad intrínseca en el grado de comunicación entre los hablantes nativos de los dos idiomas; por otro, la imperiosa exigencia de aprendices y profesores de una escrupulosa discriminación entre lo común y lo diferente, pese a su apariencia.

Esta obligación, si bien lo es en todo el sistema, se hace ineludible en el plano léxico, habida cuenta de que en otros, como el fónico o el morfosintáctico, pueden no tener que pertur- 
bar la comunicación, pese a que las diferencias de pronunciación y de construcción sean, como hemos visto, generadoras de error.

Con independencia de la exhaustividad que exigiría un estudio monográfico, presentamos a continuación una significativa relación de falsos amigos, dividida en dos columnas.

La comparación de los significantes de ambos idiomas reproduce perfectamente el efecto de error que el aprendiz no sospecha estar cometiendo. Se observará que entre los pares de voces presentados, cierto número de ellos presentan más de un significado -algunos de los cuales coincidente con el español- según los contextos en los que se usen, sin pretender, por otra parte, exponer todos los valores posibles.

\begin{tabular}{|c|c|}
\hline PORTUGUÉS & ESPAÑOL \\
\hline aceitar & aceptar \\
\hline acordar & despertar \\
\hline agasalhar & abrigar(se), arropar(se). \\
\hline afiar & afilar \\
\hline ainda & todavía \\
\hline alagar & inundar, anegar \\
\hline alavanca & palanca \\
\hline almejo / almejar & deseo vehemente /ansiar. \\
\hline almofada & cojín \\
\hline ameixa & ciruela \\
\hline ano & año \\
\hline apagar & borrar lo escrito \\
\hline apelido & apodo // hipocorístico \\
\hline asa & ala \\
\hline aterrar & aterrizar \\
\hline aula & clase, lección \\
\hline autocarro & autobús \\
\hline balcão & mostrador \\
\hline barata & cucaracha \\
\hline barulho & ruido \\
\hline borracha & goma \\
\hline brincar & jugar \\
\hline cacho & racimo \\
\hline cadeira & silla \\
\hline calça & pantalón \\
\hline camada & capa (p. ej. de ozono), extensión \\
\hline câmara municipal & ayuntamiento \\
\hline caro & querido // caro \\
\hline carro & coche \\
\hline carrinha & furgoneta \\
\hline cartão & tarjeta, carné \\
\hline chato & aburrido \\
\hline clase & categoría, especie, distribución, tipo \\
\hline
\end{tabular}




\begin{tabular}{|c|c|}
\hline colher & cuchara \\
\hline colo & regazo (Port.) // cuello $(\mathrm{Br} .: \approx$ pescoço $)$ \\
\hline condão & virtud; don, poder; (varinha de c.; 'varita mágica') \\
\hline comissária/o (de bordo) (Br.) & azafata/o \\
\hline comprido & largo \\
\hline corrente & $\begin{array}{l}\text { que corre, normal, curso del agua, electricidad // de } \\
\text { segurança: cadena metálica/ de seguridad. }\end{array}$ \\
\hline corrida & carrera (gral. y tb. taxis) // de toros. \\
\hline costas & espalda \\
\hline dado & dato // dado \\
\hline doce & dulce \\
\hline empregado & camarero \\
\hline endereço & dirección \\
\hline enganar-se & equivocarse \\
\hline engraçado & gracioso \\
\hline escova & cepillo \\
\hline escritório & oficina, despacho, agencia \\
\hline esplanada (terraço) & terraza \\
\hline esquadra (da policia) & comisaría \\
\hline esquisito & raro, extraño, excéntrico \\
\hline fantasia (Br.) & disfraz \\
\hline fechar & cerrar \\
\hline férias & vacaciones \\
\hline funda & honda, profunda \\
\hline galho & rama, racimo \\
\hline ganhar & recibir (un regalo) \\
\hline garfo & tenedor \\
\hline garrafa & botella \\
\hline grasa & gordura \\
\hline hospedeira/o (de avião) (Port.) & azafata/o \\
\hline largo & ancho \\
\hline $\operatorname{largo}($ praça) & plaza \\
\hline lenço & pañuelo \\
\hline lençol & sábana \\
\hline ligar & encender, conectar; llamar por teléfono \\
\hline $\log O$ & pronto, inmediatamente \\
\hline loiro, louro & rubio \\
\hline máscara (Port.) & disfraz \\
\hline mala & maleta \\
\hline mata & selva, bosque \\
\hline mear & dividir en dos, mediar \\
\hline miar & maullar \\
\hline molho & salsa \\
\hline móvel/móbel & mueble // causa, objetivo \\
\hline ninho & nido \\
\hline
\end{tabular}




\begin{tabular}{|c|c|}
\hline oficina & taller, taller mecánico \\
\hline osso & hueso \\
\hline passar & planchar \\
\hline passeio & acera, paseo \\
\hline pasta & cartera portafolios \\
\hline pegar & coger, tomar, agarrar // pegar \\
\hline penso (Port.) & tampón higiénico \\
\hline perceber & entender, comprender \\
\hline pescada & merluza \\
\hline pessoa grossa & persona grosera \\
\hline pneu sobressalente & rueda de repuesto \\
\hline polvo & pulpo \\
\hline planos & planes / planos \\
\hline prejuízo & perjuicio \\
\hline pressunto & jamón \\
\hline prestar un examen & hacer, presentarse a un examen \\
\hline preto & negro \\
\hline procurar & buscar \\
\hline pronto & listo \\
\hline quintal & patio \\
\hline rato & ratón \\
\hline rostro & pico de las aves ( $\neq$ rosto, 'íd.') \\
\hline sacar & arrancar, talar árboles// emitir un cheque // entender \\
\hline sede & sed // sede, aposento \\
\hline sitio & finca, espaço de terra \\
\hline sobremesa & postre \\
\hline sobrenome & apellido \\
\hline solo & suelo \\
\hline sótão & buhardilla, desván \\
\hline sucesso & éxito, triunfo \\
\hline sujo & sucio \\
\hline taça & copa \\
\hline talher & cubiertos \\
\hline talher & oficina \\
\hline talho & carnicería \\
\hline tela & pantalla de tv, de ordenador, de teléfono móvil \\
\hline tesouras & tijeras \\
\hline tinta & pintura / tinta \\
\hline tirar & sacar, quitar(se), tomar, coger. \\
\hline torcer & torcer, doblar, // apoyar, simpatizar, acompañar, \\
\hline torneira & grifo \\
\hline travesseiro & almohada \\
\hline trilha & banda sonora \\
\hline triscar & hacer ruido, alterar//Bras. acariciar \\
\hline varanda & balcón \\
\hline
\end{tabular}




\begin{tabular}{|l|l|}
\hline vaso & tiesto, maceta \\
\hline venda & venta \\
\hline vernissage & inauguración (exposición) \\
\hline visto & visado \\
\hline vocês & vosotros \\
\hline zorra & carro, carretilla \\
\hline
\end{tabular}

Parece justificarse, a la vista de esta muestra, la existencia del abultado número de secuencias erróneas que estamos analizando, y que, en nuestra opinión, no dejan demasiado lugar a la duda sobre la influencia de una interferencia directa, que se irá aminorando a medida que el aprendiz se aproxime más a la L2. Como era de prever, son incontables los casos de secuencias con desviaciones léxicas debidas a esta causa, por lo que nos limitamos a transponer aquí pequeñas pero ilustrativas muestras del fenómeno.

\begin{abstract}
*para volver usar todos mis móbiles (= 'muebles'); *caro amigo Juan; *deseo que tenga suceso; *espero que hagas mucho suceso; *quiso procurarla en la casa; *para hacer planos; *que hagamos planos juntos; *hacer mis planos; *los estudios que hacen en la mata; *La mata atlántica no es interminable; *a está desmatando (= 'deforestando'); *hacerle muchos mas prejuicios; *sufría los prejuizos de la accion del hombre; *Ahora yo me despezo ${ }^{9}$ para hacer la fantasía; *dados científicos; *estoy torcendo tus solicitudes; *tenía una bella varanda; *sacan todos los arboles; *fue una cosa muy engrasada; *sin que mi abuela percebera; *tenía un vaso con algunas plantas tropicales; *destruyendo la camada de ozonio; *Cuando vio que no acordaba más llamó a la policia (= 'se despertaba'); *Con este descubierto será posible las personas comeren el chocolate sin se preocupar del grado de gordura del chocolate; *una aula poco interesante; * No podia creer lo que estaba salendo por la tela de su ordenador; *Yo pude ver la última corrida de Ayrton Senna; *Las que son pegas van para la prisión (= 'cogidas, detenidas'); ««Melquiades» era solo una pelota de pelo que meaba bajito (= 'maullaba'); *oí unos meados que semblaban el lloro de un niño; etc.
\end{abstract}

\title{
3. ERRORES POR OMISIÓN LÉXICA
}

Existen, por otra parte, numerosos casos de errores por omisión, es decir, aquéllos debidos a la ausencia de una unidad léxica esperable que no ha sido producida en su contexto, y en lugar de la cual encontramos una paráfrasis descriptiva o un sinónimo inadecuado, en una evidente estrategia de sustitución que podríamos llamar indirecta, en el caso de las perífrasis, o directa, en caso de recurrir a un sinónimo. Se trata de solucionar un problema de desconocimiento, real o supuesto, de una unidad léxica, para lo cual el informante recurre a la sustitución.

Anotamos aquí la existencia de un desconocimiento supuesto, dado que no es infrecuente asistir a casos de lo que podríamos llamar redescubrimento por retorno. Denominamos así al fenómeno que se produce cuando el estudiante considera, por ultracorrección, que la palabra o expresión que él cree que debe usar se parece demasiado a la correspondiente en su LM, por lo que se aleja de ésta en un intento de hallar o recordar la adecuada. Cuando el diccionario o cual-

9 Aunque no existe posible confusión entre los infinitivos de los verbos en español y en portugués (pedir, despedir, expedir, impedir, medir, etc.), no ocurre lo mismo con la $1^{\mathrm{a}}$ persona del presente de indicativo (eu peço, eu despeço, etc.) y con todas las del de subjuntivo (eu peça, eu despeça, etc.). 
quier otro informante le proporciona la voz correcta, se produce una especie de repliegue a su intuición primera, la descartada, y redescubre que, por ejemplo, «mesa» en español se escribe «mesa».

Este proceso de avance por retroceso, si se nos permite la antítesis, no está, sin embargo, exento de peligro por cuanto encierra una ratificación en términos idénticos, en efecto, pero favorece la presencia de los falsos amigos que veíamos más arriba.

Sea real o supuesto, el desconocimiento léxico fuerza al estudiante a la búsqueda de soluciones, marcadas en numerosas ocasiones, por un error de precisión que, dependiendo de la proximidad a la norma, facilitará más o menos la comunicación:

*una sala donde se vigila por los muertos; *quieren llamarme en la Justicia (= 'denunciarme'); * para irmos a nuestro piso de arriba; *del parte del gallo de la cabeza, como peina o... corona (= 'cresta'); *los satélites de ojo que usan para saber el tiempo; *una academia de gimnástica; *Camila se pone de cama a causa de una gripe; *unas lunares rojas en la cara pelo sol; *Me puse de color rojo; *haciendo quemadas (= 'haciendo hogueras / fogatas'; 'incendiando'); *la Amazónia está cada vez más sin verde; *si no fuese por las vacunas, muchas personas tendrían se acabado; *para darle baño al gato (= 'bañarlo'); *han matado la persona primera del gobierno (= 'presidente'); *lo más viejo de los hermanos (= 'el mayor'); etc.

La estrategia es evidente y cumple perfectamente la función comunicativa, al menos para solventar las necesidades de intercambio de información. Pero a la hora de corregir y evaluar, este hecho vuelve a plantear el dilema entre premiar la capacidad del aprendiz por superar un obstáculo y punir la falta de precisión o el desconocimiento de unidas léxicas que deberían estar sistematizadas. No es sino el tantas veces citado problema entre la comunicatividad y la corrección que no podía sustraerse del plano léxico.

\section{CONCLUSIONES}

La aproximación al aprendizaje del léxico de una segunda lengua significa una tarea de tal magnitud que requiere un esfuerzo ímprobo por parte del estudiante (y del profesor), toda vez que desde los primeros minutos del aprendizaje descubre que sin las palabras es incapaz de comunicar lingüísticamente nada, algo que no sucede sin las estructuras sintácticas, como puede comprobarse al observar a un extranjero en situaciones de interactuación al intentar, por ejemplo, comprar o tomar algo en una cafetería, para lo cual le bastará (además del lenguaje de señas) usar las palabras, es decir, los nombres de las cosas que desee adquirir, sin necesidad de usar estructuras sintácticas, como le ocurre, por otra parte, al niño que pide, pronunciando a su manera las palabras que designan las cosas.

Esa precariedad lingüística o, más exactamente, lexicológica, parece solventarse de alguna forma cuando los idiomas en contacto son tan aparentemente próximos como se pretende que sen el portugués y el español, por lo que los estudiantes de ambos lados se sienten aliviados al comprobar que mesa se escribe mesa en los dos idiomas, independientemente de que su sonido sólo sea parecido (con las consecuencias fonéticas y ortográficas que pudieran derivarse), realidad a la que sólo prestará atención mucho más adelante en el estudio, aunque esto tampoco ocurre con la frecuencia deseada.

El problema surge, como hemos visto, cuando los aprendices empiezan a estudiar la otra lengua en lo que podríamos calificar como in medias res, sin dedicar demasiado tiempo a cono- 
cer cuáles son las diferencias iniciales entre ambos idiomas, entre las que ocupan un lugar preponderante la fonética y el léxico, si se observa, los dos elementos fundamentales para, precisamente, empezar a estudiar/hablar una lengua.

Ciñéndonos a nuestro estudio, el estudiante lusófono (el hispanohablante en el sentido contrario del aprendizaje) sufre como pocos la influencia de las interferencia, las transferencias negativas, porque descubre, aplica y desarrolla, de forma inconsciente, la aparente facilidad de la interferencia de su propia lengua, con lo que podemos decir que realmente no estudia léxico, sino que busca el que se parece al suyo, y en estas dos lenguas los parecidos son tan abundantes y hay tal cantidad de falsos amigos, que es casi comprensible que se produzca una relajación en el estudio. Y decimos «de forma inconsciente» porque la estrategia de buscar lo similar constituye un mecanismo involuntario que se desarrolla en el aprendizaje, como se hace cuando se intenta estudiar una lengua absolutamente diferente, al menos en los primeros momentos del estudio. Por esa razón, quizá sería cuestionable ejercer una sanción correctora demasiado severa ante esos primeros errores por interferencia, si no va acompañada de una «reeducación» previa de lo ya sabido por existir en la lengua materna. Se trataría casi de reformatear la memoria de la LM para que no se use como recurso en el momento de adquirir nuevo léxico.

Por otra parte, la comprobación de los errores por lo que hemos llamado intraferencia significa una doble exposición a los elementos distorsionadores, la interferencia externa (la del portugués como lengua materna) y la interna (la causada por la analogía de lo que va aprendiendo), si bien debe observarse que los momentos de máxima virulencia de ambas se producen de forma escalonada: la interferencia de la lengua materna actúa más al principio, cuando más débil (o inexistente) es el conocimiento del español (piénsese, por ejemplo, en la pronunciación o, por supuesto, en los heterosemánticos en el léxico), mientras que la segunda comienza a actuar cuando el estudiante ya ha adquirido cierto conocimiento y empieza a padecer la tentación de la analogía de lo que ya ha aprendido. En otras palabras, pasa de aplicar la analogía de su lengua a hacerlo con lo que sabe de la nueva, en este caso, del español.

Como decíamos al principio, el estudio del léxico exige una dedicación intensa en cualquier caso, pero es quizá entre estudiantes de las dos lenguas comparadas donde el aprendizaje exige una profunda labor de análisis por parte del estudiante y del profesor, tarea que debe hacerse desde el primer momento, sin dejar el menor resquicio para la tentación de lo aparentemente similar, por la sencilla razón de que cuanto más se facilite el aprendizaje, buscando solo lo igual, más difícil será después erradicar de forma efectiva los errores fosilizados que suelen acompañar para siempre a los hablantes de cada una de las lenguas que se expresan en la otra. 


\section{REFERENCIAS BIBLIOGRÁFICAS}

ANDERSEN, R. W. (1983): «Transfer to somewhere», en S. Gass y L. Selinker, eds., Language Transfer in Language Learning. Newbury House, Rowley, Mass, pp. 177-201.

Bosque, I. y V. Demonte, (eds.) (1999): Gramática descriptiva de la lengua española, Madrid, Espasa.

Buarque de Holanda Ferreira, A. (1999): Novo Aurélio Século XXI: O Dicionário da Língua Portuguesa, Rio de Janeiro, Nova Fronteira.

Cipro neto, P. y U. Infante (1999): Gramática da língua portuguesa, São Paulo, Editora Scipione.

Clark, E. (1993): The Lexicon in Acquisition, Cambridge, Cambridge University Press.

CORDER, S. P. (1981): Error Analysis and Interlanguage, Oxford, Oxford University Press.

De CAstro, M. (1999): «Las connotaciones socioculturales en el proceso de adquisición del léxico», en L. Miquel y N. Sans, eds., Didáctica del español como lengua extranjera, Cuadernos Tiempo Libre, Madrid, Fundación Actilibre, pp. 67-86

De SÁ nOgueIRA, R. (1986): Dicionário de verbos portugueses, Lisboa, Clássica Editora.

DurÃo, A. B. DE A. B. (1999): Análisis de errores e interlengua de brasileños aprendices de español y de españoles aprendices de portugués, Londrina, UEL. (2007): La interlengua, Madrid, Arco/Libros.

ElLIS, R. (1994): The Study of Second Language Acquisition, Oxford, Oxford University Press.

FATHMANN, A. (1975): «The relationship between age and second language productive ability», Language Learning, 25, pp. 245-253.

Instituto Antônio Houaiss (2001): Dicionário Houaiss da Língua Portuguesa, Rio de Janeiro, Objetiva.

Krashen, S., R. Scarcella y M. Long, eds. (1982): Child-Adult Differences in Second Language Acquisition, Rowley, Mass., Newbury House.

LADO, R. (1957): Linguistics across Cultures: Applied linguistic for Language Teachers, Ann Arbor, University of Michigan Press.

LóPez Morales, H. (1993): Sociolingüistica, Madrid, Gredos.

Naiman, N., M. Fröhlich, H. Stern y A. Todesco (1978): The Good Language Learner, Toronto, The Ontario Institute for Studies in Education.

NorRish, J. (1983): Language Learners and Their Errors, London, MacMillan Publishers.

OYAMA, S. (1976): "A sensitive period in the acquisition of a non-native phonological system», Journal of Psycholinguistic Research, 5, pp. 261-285.

(1985): The Ontogeny of Information: Developmental Systems and Evolution, Cambridge, Cambridge University Press.

Real Academia Española (1992): Diccionario de la lengua española, Madrid, Espasa-Calpe.

REISs, M. (1985): «The good language learner: another look», Canadian Modern Language Review, 41, pp. 511-523.

RODRÍGUEZ LEDESMA, M. N. (1996): «Un caso paralelo de degradación semántica en inglés y español», en M. Martínez Vázquez, ed., Gramática contrastiva inglés-español, Huelva, Universidad de Huelva, pp. 245-263. 
Romero SILVA, L. M. T. (2000): Análisis de errores léxicos en el español de estudiantes brasileños, Memoria inédita final del Máster «Lengua y cultura españolas» de la Universidad de Salamanca.

Santos gargallo, I. (1993): Análisis Contrastivo, Análisis de Errores e Interlengua en el marco de la Lingüistica Contrastiva, Madrid, Síntesis.

SELls, P. (1985): Lectures on Contemporary Syntactic Theories: An Introduction to Government, Binding Theory, Generalized Phrase Structure Grammar and Lexical-Functional Grammar, Chicago, University of Chicago Press.

Singleton, D. (1992): Language Acquisition: The Age Factor, Clevedon, Multilingual Matters.

Spolsky, B. (1989): Conditions for Second Language Learning, Oxford, Oxford University Press.

TORIJANO, J. A. (2003): Análisis teórico-práctico de los errores gramaticales en el aprendizaje del español, L-2: expresión escrita, Salamanca, Universidad de Salamanca.

- (2004): Errores de aprendizaje, aprendizaje de los errores, Madrid, Arco/Libros.

(2006a): «Conciencia de error en los buenos aprendices residentes en países hispanohablantes», en J. M. Bustos Gisbert y J. Sánchez Iglesias, coords., La fosilización en la adquisición de segundas lenguas: el buen aprendiz, Salamanca, Hispano Lusa de Ediciones.

- (2006b): «Lo que nos enseñan los errores», Revista Signum: Estudos da Linguagem, pp. 143-205.

VArela Ortega, S. (2003): «Léxico, morfología y gramática en la enseñanza de español como lengua extranjera», ELUA, 17, pp. 571-588.

WeInRICH, U. (1974): Languages in Contact, La Haya, Mouton. 